\title{
ANALYSIS OF DIALLEL CROSSBREEDING IN CHICKENS BY REML AND ANOVA METHODS
}

\author{
M. H. Khalil* and G. Abou Khadiga ${ }^{\dagger, 1}$
}

*Dep. of Poult. Prod., Fac. of Agric., Alexandria Uni., Egypt; and †Fac. of Desert and Enviro. Agric., Fuka, Matrouh Uni., 51744 Matrouh, Egypt

${ }^{1}$ Corresponding author: M. H. Khalil Email: mohamedhassankhalil@yahoo.com Received: $25 / 08 / 2020$ Accepted: 09/09/2020

\begin{abstract}
The current experiment was carried out to compare REML-based to ANOVA-based methods (Griffing, Cockerham, Henderson) in estimation of crossbreeding genetic parameters in chicken experiments. The current experiment involved a full $4 * 4$ diallel crossing among four Egyptian breeds (Alexandria (AA), Fayoumi (FF), Matrouh (MM) and Golden Montazah (GG). The studied traits were body weight at hatch (BWH), body weight at 4 weeks of age (BW4), body weight at 8 weeks of age (BW8) and body weight at 12 weeks of age (BW12). The general comparison among models showed the superiority of REML-based method, especially in prediction ability with significant difference. A close comparison between REML and Griffing methods showed consistency between both methods with the advantage of accurate estimation and prediction ability of the REML-based method. The analysis of the empirical data showed the superiority of the AA line in general combining ability (GCA). The genotypes of MG, FM and AG showed the highest specific combining ability (SCA) in the end of the experiment at 12 weeks of age.
\end{abstract}

Key word: Diallel crossbreeding, Genetic parameters, REML, ANOVA 


\section{INTRODUCTION}

Crossbreeding between lines with different genetic background is mostly result in progeny with better performance abilities compared with their parents. Systematic crossbreeding has been used successfully within livestock species (Ragab et al., 2014; Amin, 2015; Okoro and Mbajiorgu, 2017). A diallel crossbreeding system is a set of possible combinations between lines, breeds or general populations which is used to evaluate the performance of parents providing information about the most promising crosses within a genetic pool (Jakubec et al., 1987). Using this system in animal breeding programs facilitates the evaluation of crossbreeding genetic parameters Such as combining ability (general and specific) and heterotic potential crossbreds resulting of mating different lines (Clasen et al., 2017). The diallel analysis provides essential crossbreeding parameters such as heterotic effects. It also manifests the role of additive effects and non-additive effects through the general combining ability (GCA), and specific combining ability (SCA), respectively (Vencovsky, 1987). Genetic effects could be treated as fixed or random depending on the aim of estimation. Griffing (1956) proposed four different experimental methods under ANOVA framework based on the performance of the crosses that provides estimates of general combining ability (GCA) and specific combining ability (SCA). Each of these methods has its peculiar mathematical model of analysis (fixed, random or mixed), depending on the study objectives. Setting the parameters as fixed are the most common form due to the calculation simplicity (Resende 1999). However, recent reports show that the use of mixed linear models allows obtaining the genetic parameters and the variance components through the restricted maximum likelihood (REML). One advantage of mixed linear models is its flexibility which help in aid of selection bias in selection experiments. Moreover, it allows for genotype prediction through the Best Linear Unbiased Prediction (BLUP), as well as, estimation of fixed effects (BLUE), simultaneously. These advantages help breeders through providing inferences about the genetic value (Resende 1999, Resende and Duarte, 2007) and prediction of genetic values of each individual even if it belongs to notperformed crosses (Bernardo 1996). As a result, the bigger the number of genotypes the larger the information obtained on combining ability, even on missing combinations. The use of mixed models (Panter and Alten 1995) would help in prediction of the genotypes under different environments by dealing with the genetic effects as random effects adjusting them to the other fixed effects in the model (Valério et 1., 2009). This would be helpful in evaluation of genotypes during the analysis of their performance in breeding programs under harsh environmental influence (Falconer and Mackay 1996). Therefore, the objective of this study was to evaluate two diallel analysis models, Griffing's (fixed) and BLUP (random), with regard to their combinatory effects and predicting ability of non-tested groups for sixteen chicken genotypes consisting a $4 \times 4$ diallel crossing.

MATERIALS AND METHODS birds and management conditions

The current study was conducted at the Poultry Research Center, Poultry Department, Faculty of Agriculture, Alexandria University, Egypt. A total number of 1776 of pedigreed chickens were obtained from sixteen different genetic groups by mating four local Egyptian chickens (Alexandria, Fayoumi, Matrouh and Golden Montazah) in a full 4*4 diallel crossbreeding system through five consecutive hatches. The birds were distributed to sixteen pens in the farm. Every pen contained 4 sires of each breed allowing every single sire to mate with 


\section{Diallel crossbreeding, Genetic parameters, REML, ANOVA}

three females of its own breed and one female from each of the other three breeds. Management conditions were similar throughout the experiment.

\section{Traits}

The studied traits were individual body weight in grams every 4 weeks from hatch to 12 weeks of age (BW0, BW4, BW8 and BW12).

\section{Statistical analysis}

All analyses were carried out under R environment (version 3.5.1, 2018). Package lsmeans (Lenth, 2016) was used to estimate least squares means and their standard errors for body weight at different ages from hatch up to 12 weeks of age according to the following model:

$Y_{i j k l}=\mu+G_{i}+S_{j}+H_{k}+G S_{i j}+G H_{i k}+$ $S H_{j k}+G H S_{i j k}+e_{i g k l}$,

where: $\mathrm{Y}_{\mathrm{ijkl}}=$ the observation on the genotype, $\mu=$ the overall mean, $\mathrm{G}_{\mathrm{i}}=$ the fixed effect of $i^{\text {th }}$ genotype, $S_{j}=$ the fixed effect of $j^{\text {th }}$ sex, $\mathrm{H}_{\mathrm{k}}=$ the fixed effect of $\mathrm{k}^{\text {th }}$ hatch, $\mathrm{GS}_{\mathrm{ik}}, \mathrm{GH}_{\mathrm{ij}}, \mathrm{SH}_{\mathrm{jk}}$ and $\mathrm{GHS}_{\mathrm{ijk}}=$ the interaction between the fixed effects, and $\mathrm{e}_{\mathrm{igkl}}=$ random error.

The package sommer (CovarrubiasPazaran, 2016) was used to apply different diallel crossing models to estimate crossbreeding parameters and to compare models for their predicting ability. The general model included the effects of genetic group (16 levels), sex (male or female) and hatch (5 levels). The values of the common parameters in all models were compared according to the Tukey test. All significance tests were based on the 0.05 level.

Two types of models were used to estimate crossbreeding genetic parameters as general combining ability (GCA), specific combining ability (SCA), and reciprocal effects (RE) of the current experiment. The first is ANOVA type models which included three models as

1-Griffing method 1 (Griffing, 1956):

$\mathrm{y}_{\mathrm{ij}}=\mu+g_{i}+g_{j}+\mathrm{s}_{i j}+\delta r_{i j}+e_{i j}$

where

$\mu$ : general mean $\mathrm{g}_{\mathrm{i}}$ : general combining ability of the $\mathrm{i}^{\text {th }}$ purebred population

$\mathrm{s}_{\mathrm{ij}}$ : specific combining ability for the combination $\mathrm{i} \times \mathrm{j}$

$r_{i j}$ : reciprocal effect for the combination $i$

$\mathrm{x} \mathrm{j}$

$\mathrm{e}_{\mathrm{ij}}$ : residual effect

2-Cockerham (1963):

$\mathrm{y}_{\mathrm{ij}}=\mu+g_{i}+g_{j}+m_{j}+S i j+\delta r_{i j}+e_{i j}$

where

$\mu$ : general mean

$g_{i}$ general combining ability of the $i^{\text {th }}$ purebred population

$\mathrm{m}_{\mathrm{j}}$ : maternal effect of the $\mathrm{j}^{\text {th }}$ purebred population

$\mathrm{S}_{\mathrm{ij}}$ : specific combining ability for the combination $\mathrm{i} \times \mathrm{j}$

$r_{i j}$ : residual reciprocal effect for the combination $\mathrm{i} \times \mathrm{j}$

$\mathrm{e}_{\mathrm{ij} \text { : }}$ residual effect

3-Henderson (1948):

$\mu+(1-\delta)\left(a_{1}+p_{i}\right)+\delta\left(a 2+g i+m_{j}+c i j+\right.$ $\left.r_{i j}\right)+e_{i j}$

where

$\mu$ : general mean

$\mathrm{a}_{1}$ : effect common to all purebred populations

$\mathrm{a}_{2}$ : effect common to all crossbred populations

$\mathrm{p}_{\mathrm{i}}$ : effect common to all progeny of a mating between a dam from the ith line with a sire

from the $\mathrm{i}^{\text {th }}$ line

$\mathrm{g}_{\mathrm{i}}$ : general combining ability of the $\mathrm{i}^{\text {th }}$ purebred population

$\mathrm{m}_{\mathrm{j}}$ : maternal effect of the $\mathrm{i}^{\text {th }}$ purebred population

$\mathrm{S}_{\mathrm{ij}}$ : specific combining ability for the combination $\mathrm{i} x \mathrm{j}$

$\mathrm{r}_{\mathrm{ij}}$ : residual reciprocal effect for the combination $\mathrm{i} x \mathrm{j}$

$\mathrm{e}_{\mathrm{ij}}$ : residual effect

The second type of models was a REMLbased model as:

$y=X r+Z a+W f+e$,

where: $y$ is the data vector; $r$ is the vector of replication effects (assumed as fixed) added to the general mean; $a$ is the vector of individual additive genetic effects 
(assumed as random); $f$ is the vector of full-sib line dominance effects (random); $e$ is the vector of errors or residues (random), and $X, Z$ and $W$ are incidence matrices for these effects. The GCA, SCA, reciprocal effects, and error term were considered random to allow an estimation of their variance whilst the effect of batch was considered fixed to account for some potential bias induced by carrying out the experiment in batches. To evaluate the GCA values of parental lines, BLUPs of the GCA effects were also computed.

\section{Model comparison}

Models were compared according to their capability in the goodness-of-fit criteria to the data of body weight of crossbred chicks. The comparison criteria were determination coefficient $\left(R^{2}\right)$, mean square error (MSE), Schwarz information criterion (BIC), and predicting ability $(\rho)$. To test the predicting ability of the models, $25 \%$ of the records of every genetic group were masked by setting it as missed. Correlations between the observed and the predicted data in the validation set were used to compare models.

\section{RESULTS AND DISCUSSION}

A comparison among all models for their characteristics are presented in Table 1. The comparison showed that REMLbased model had similar means to Griffing and Cokerham models for all traits. However, Henderson model had slightly higher values for means for all traits compared with other models. It also had the lowest $R^{2}$ and $\rho$ among the studied models. The REML-based model showed the lowest MSE compared with the other models for all traits. $R^{2}$ values were higher than $99 \%$ for all models in all traits. The REML-based model scored the highest values (99.99) in all traits. In addition, the REML-based model showed the highest prediction ability $(\rho)$ among all models in all traits. The differences in $\rho$ between the REML-based model and the other models were significant showing an increased trend with age advance.
In the framework of mixed linear model methodology, the fixed effects are estimated by the Best Linear Unbiased Estimator (BLUE) and random effects are predicted by the Best Linear Unbiased Prediction (BLUP). A major advantage of this methodology is its prediction ability of genetic values of each individual, and prediction of not-performed or missing crossbred genotypes (Bernardo 1996). The methodology depending on treating genetic effects as random and adjust them for the fixed effects of the model. It also has the advantages in designs with high unbalanced orders. The advantages of this methodology could interpret its consistency and superiority over other methods.

Spearman's correlation coefficients $(r)$ between REML-based and Griffing models, for the general and specific combining ability parameters (GCA and SCA) and reciprocal effects (RE) for body weight traits are presented in Table 2. It was observed that the association between both types of models had a decreasing trend from hatch age to 12 weeks of age. All correlation coefficients were high $(>0.9)$ at all times. However, variation in values of both types of models did not show a typical estimation, as can be observed by the correlation estimates. Therefore, both models should be evaluated carefully in the matter of joint analysis to obtain a more precise estimate. Estimates of general and specific combining ability parameters (GCA and SCA) and reciprocal effects (RE) are shown in Table 3. GCA estimates were significant among the purebreds for BW at different ages. SCA estimates showed the superiority of the crosses (FG, MG and $\mathrm{FM})$ for BW4, BW8 and BW12, respectively. GCA estimates in a descending order were AA, GG, MM and then FF showing the superiority of AA genotype over the other genotypes except at hatch where AA was ranked second after GG genotype. The GCA estimates of 
AA and GG were always positive, while negative estimates were observed for MM and FF genotypes for BW at all ages. The ranges of GCA were -2.09 to $1.85,-3.77$ to $4.53,-18.79$ to 27.33 and -34.47 to 61.42 for BWH, BW4, BW8 and BW12, respectively.

The ranges of SCA estimates were -1.06 to $0.53,-2.94$ to $6.41,-6.35$ to 21.96 and 21.67 to 4.55 for BWH, BW4, BW8 and BW12, respectively. There was no consistent trend of superiority of any specific genotype along the entire study. However, it could be observed that the breed A-sired genotypes (AG and $\mathrm{AM}$ ) recorded the lowest SCA in all ages except at 12 weeks of age compared with the other genotypes. Particularly, the genotype AM showed the least SCA estimates at the middle phase of growing at 4 and 8 weeks of age. At the same ages, the breed-F genotypes represented the highest SCA as male (AF) or female (FG and FM) compared with other genotypes.

The ranges of RE were -0.70 to $2.42,-5.97$ to $13.70,-16.83$ to 24.51 and -49.31 to 39.32 for BWH, BW4, BW8 and BW12, respectively. An increasing trend of $\mathrm{RE}$ estimates was observed for all genotypes with age advance. The genotype MF was superior to all other genotypes at all ages, while the genotype FA was inferior to all of them at all ages.

One reason of GCA importance is its relation to the high efficiency and ease of selection process. This could be attributed to prevailing additive effects involved in the trait expression. The diallel analysis unveils the role of additive effects through GCA allows in detection of the desirable combiner genotypes to exploit heterosis. Gardner and Eberhardt (1966) defined GCA as an average performance of a line in different hybrid combinations. The estimates of GCA reflect the importance of additive gene effects of breeds on body weight at different ages (Afifi et al., 2002). The significance of GCA effects indicated the importance of additive genetic variance. This confirms the results of Mekki et al. (2005); Razuki and AlShaheen (2011). The differences in BW between these genotypes give good chance to select among them to improve their weight. The GCA effects of breeds (Table 3 ) indicated superiority of AA for BW and BWG at 4, 8, and 12 wk of age. While, FF had least GCA effect.

The significance of genetic effects is divided into variability among GCA effects, which could be attributed to additive gene effects, and among SCA effects, where non-additive gene effects play the great role (Cruz et al. 2004). In the current study, high GCA and SCA mean square values could be an indicator to the importance of additive genetic effects rather than non-additive genetic effects.

SCA could be defined as a numerical value that expresses the deviation of a specific cross compared to what would be expected from the average performance of the lines involved in that cross. As such, SCA is a result of either dominance or epistasis, or a combination of the two (Gardner and Eberhardt 1966). The contribution from SCA was highly significant for BW and BWG during all studied ages (Table 3). The cross (FM) had the highest SCA for BW at 8 wk of age, and BWG at 4-8 and 8-12 wks of age. While, the cross (MG) was superior in SCA for BW at 12 wks of age, and BWG at 4-12 wks of age. In addition, the cross (FG) was superior in SCA for BW at 4 wks of age (Table 3 ). This indicated the importance of nonadditive genetic effects for growth performance during this experiment, so reciprocal recurrent selection would be advantageous to exploit non-additive gene action in these crosses.

Similar results were reported in the literature (Saadey et al., 2008; Adebambo et al., 2011; Siwendu et al., 2013). They reported positive SCA estimates for BW at different ages. The additive effects were generally more important than dominance in determining BW. This was corroborated 
by the higher values of GCA than SCA (Table 3). These results were supported by the work of Mekki et al. (2005) and Adebambo et al. (2011). This indicator that selection will be better tool to improve this trait. Detection of the potentiality of a group of genotypes considering the positive SCA values and high GCA of one parent is a must (Cruz et al. 2004). Regarding the ranking of best genotypes, the SCA of the studied traits was not coincident. Therefore, the results in this matter should be considered cautiously.

Reciprocal effects (RE) were significant for BW during all studied ages. The cross (MF) had the maximum RE, while the cross (FA) had the least RE for BW at different ages (Table 3). These results suggested that MF cross was superior to FM cross in sex linked gene effect. The

Table (1): Model comparison

\begin{tabular}{|c|c|c|c|c|c|}
\hline & \multicolumn{4}{|c|}{ Models } & \multirow{2}{*}{$\begin{array}{l}P \text {-value of } \\
\text { the } \\
\text { prediction } \\
\text { ability }\end{array}$} \\
\hline & Griffing & Cockerham & Henderson & REML & \\
\hline Parameters & \multicolumn{5}{|c|}{ BWH } \\
\hline $\begin{array}{l}\text { Mean } \\
\text { MSE } \\
R^{2} \\
\rho \\
\end{array}$ & $\begin{array}{c}36.08 \\
552.18 \\
99.97 \\
95.67 \\
\end{array}$ & $\begin{array}{c}36.08 \\
555.667 \\
99.96 \\
95.23 \\
\end{array}$ & $\begin{array}{c}36.12 \\
553.00 \\
99.91 \\
94.05\end{array}$ & $\begin{array}{c}36.08 \\
550.11 \\
99.99 \\
97.32 \\
\end{array}$ & 0.0424 \\
\hline$\rho$ & \multicolumn{5}{|c|}{ BW4 } \\
\hline $\begin{array}{l}\text { Mean } \\
\text { MSE } \\
R^{2} \\
\rho\end{array}$ & $\begin{array}{c}212.07 \\
1912.41 \\
99.96 \\
93.88\end{array}$ & $\begin{array}{c}212.07 \\
1914.88 \\
99.93 \\
93.16\end{array}$ & $\begin{array}{c}210.22 \\
1921.28 \\
98.64 \\
92.05\end{array}$ & $\begin{array}{c}212.07 \\
1910.45 \\
99.99 \\
94.11\end{array}$ & 0.0487 \\
\hline$\rho$ & \multicolumn{5}{|c|}{ BW8 } \\
\hline $\begin{array}{l}\text { Mean } \\
\text { MSE } \\
R^{2} \\
\rho\end{array}$ & $\begin{array}{c}530.55 \\
7806.98 \\
99.97 \\
90.90\end{array}$ & $\begin{array}{c}530.55 \\
7809.62 \\
99.96 \\
90.00\end{array}$ & $\begin{array}{c}527.66 \\
7815.77 \\
99.91 \\
89.33\end{array}$ & $\begin{array}{c}530.55 \\
7800.25 \\
99.99 \\
93.52\end{array}$ & 0.0312 \\
\hline$\rho$ & \multicolumn{5}{|c|}{ BW12 } \\
\hline $\begin{array}{l}\text { Mean } \\
\text { MSE } \\
R^{2} \\
\rho\end{array}$ & $\begin{array}{c}910.48 \\
33443.00 \\
99.97 \\
87.52\end{array}$ & $\begin{array}{c}910.48 \\
33448.55 \\
99.96 \\
85.56\end{array}$ & $\begin{array}{c}912.52 \\
33470.13 \\
99.91 \\
84.95\end{array}$ & $\begin{array}{c}910.48 \\
33430.21 \\
99.99 \\
90.24\end{array}$ & 0.0256 \\
\hline
\end{tabular}

MSE: Mean Square Error; $R^{2}$ : Coefficient of determination; $\rho$ : Prediction ability. existence of reciprocal cross differences for BW in broilers is well documented (Shebl et al., 1990; Razuki and AlShaheen, 2011; Siwendu et al., 2013). They reported important reciprocal effects for BW in crosses between different breeds of chickens. They revealed that reciprocal effects could be attributed to sex linkage.

\section{CONCLUSION}

In conclusion, this study recommended the use of the (MM) breed to cross advantageously the breeds (FF and GG) for growth traits (BW and BWG) to produce commercial broilers (FM and MG). In addition, this study suggested the use of crossbreeding tool to develop new synthetic breeds suitable to Egyptian conditions with acceptance performance. 
Diallel crossbreeding, Genetic parameters, REML, ANOVA

Table (2): Spearman's correlation coefficients $(r)$ between REML-based and Griffing models, for the general and specific combining ability parameters (GCA and SCA), and reciprocal effects (RE) for body weight traits

\begin{tabular}{|l|c|c|c|c|}
\hline Parameters & \multicolumn{4}{|c|}{ Traits } \\
\hline & BWH & BW4 & BW8 & BW12 \\
\hline General combining ability & 1.00 & 0.97 & 0.96 & 0.94 \\
Specific combining ability & 0.98 & 0.96 & 0.95 & 0.93 \\
Reciprocal effects & 0.97 & 0.95 & 0.94 & 0.92 \\
\hline
\end{tabular}

BWH: Body weight at hatch; BW4: Body weight at 4 weeks of age; BW8: Body weight at 8 weeks of age and BW12: Body weight at 12 weeks of age

Table (3): Crossbreeding genetic parameters for body weight at different ages estimated by REML method

\begin{tabular}{|l|c|c|c|c|}
\hline \multirow{2}{*}{ Parameters } & \multicolumn{4}{|c|}{ Traits } \\
\cline { 2 - 5 } & BWH & BW4 & BW8 & BW12 \\
\hline \multicolumn{5}{|c|}{ General combining ability (GCA) } \\
\hline AA & $0.39 \pm 0.13$ & $4.53 \pm 1.22$ & $27.33 \pm 3.13$ & $61.42 \pm 4.12$ \\
FF & $-2.09 \pm 0.18$ & $-3.77 \pm 0.99$ & $-18.79 \pm 2.91$ & $-34.47 \pm 3.45$ \\
GG & $-0.14 \pm 0.07$ & $-2.18 \pm 0.97$ & $-13.02 \pm 2.12$ & $-30.61 \pm 3.25$ \\
\hline \multicolumn{5}{|c|}{ Specific combining ability (SCA) } \\
\hline AF & $1.85 \pm 0.17$ & $1.42 \pm 0.78$ & $4.48 \pm 1.50$ & $3.66 \pm 1.34$ \\
AM & $0.53 \pm 0.03$ & $-2.80 \pm 0.55$ & $-3.17 \pm .80$ & $-7.60 \pm 1.13$ \\
AG & $0.16 \pm 0.03$ & $-2.94 \pm 0.62$ & $-6.35 \pm .96$ & $-7.99 \pm 1.04$ \\
FM & $-1.06 \pm 0.03$ & $4.54 \pm 0.66$ & $15.69 \pm 1.44$ & $20.02 \pm 1.88$ \\
FG & $0.31 \pm 0.01$ & $4.91 \pm 0.54$ & $21.96 \pm 1.65$ & $28.45 \pm 1.95$ \\
MG & $0.03 \pm 0.01$ & $6.41 \pm 0.71$ & $13.85 \pm 0.84$ & $-21.67 \pm 1.67$ \\
\hline \multicolumn{5}{|c|}{ Reciprocal effects } \\
\hline FA & $-0.19 \pm 0.01$ & $2.36 \pm 0.34$ & $9.10 \pm 1.11$ & $40.55 \pm 2.26$ \\
MA & $-0.70 \pm 0.03$ & $-5.97 \pm 1.33$ & $-16.83 \pm 1.33$ & $-49.31 \pm 2.66$ \\
GA & $-0.40 \pm 0.03$ & $0.75 \pm 0.22$ & $3.56 \pm 0.38$ & $-10.70 \pm 1.31$ \\
MF & $0.48 \pm 0.02$ & $4.99 \pm 1.24$ & $8.80 \pm 1.14$ & $20.91 \pm 1.36$ \\
GF & $2.42 \pm 0.03$ & $13.70 \pm 1.87$ & $24.51 \pm 1.99$ & $39.32 \pm 1.44$ \\
GM & $2.09 \pm 0.03$ & $2.96 \pm 0.53$ & $11.11 \pm 0.94$ & $21.48 \pm 1.12$ \\
\hline
\end{tabular}

Males are listed first in cross, AA: Alexandria, FF: Fayoumi, MM: Matrouh, GG: Golden Montazah 


\section{REFERENCES}

Adebambo, A. O., Ikeobi, C. O. N., Ozoje, M. O., Oduguwa, O. O. and Adebambo, O. A. 2011.Combining abilities of growth traits among pure and crossbred meat type chickens, Archivos de zootecnia, 60 (232), 953963.

Afifi, E. A., Iraqi, M. M., El-Labban, A. M., and Afram, M. 2002. Evaluation of heterosis and combining abilities for body weight traits in chickens, Ann. Agric. Sci. Mosh., 40, 2002, 857-870.

Amin, E. M. 2015. Genetic components and heterotic effect of growth traits in $3 \times 3$ diallel crossing experiment inchickens. Journal of American Science: 11(1)

Bernardo, R. 2006. Best linear unbiased prediction of maize single-cross performance. Crop Science 36: 50-56.

Clasen, J. B., Norberg, E., Madsen, P., Pedersen, J. and Kargo, M. 2017. Estimation of genetic parameters and heterosis for longevity in crossbred Danish dairy cattle. J. Dairy Sci. 100:6337-6342.

https://doi.org/10.3168/jds.2017-12627

Cockerham, C. C. 1963. Estimation of genetic variances. In: Hanson, W.D. and Robinson, H.F. (eds.), Statistical Genetics and Plant Breeding, NACNRC 982, Washington D.C., 53 - 94.

Covarrubias-Pazaran. 2016. Genome assisted prediction of quantitative traits using the $\mathrm{R}$ package sommer." PLoS ONE, 11, 1-15.

Cruz, C. D., Regazzi, A. J. and Carneiro, P. C. S. 2004. Modelos biométricos aplicados ao melhoramento genético. Universidade Federal de Viçosa, Viçosa, 480p.

DOI: https://doi.org/10.2527/jas20137286

Falconer, D. S., and T. F. C . Mackay. 1996. Introduction to quantita- tive genetics. 4th ed. Longman Scientific and Technical, Burnt Mill, Harlow, UK.
Gardner, C. O. and Eberhart, S. A. 1966. Analysis and interpretation of the variety cross diallel and related populations. Biometrics 22: 439-452.

Griffing, B. 1956. Concept of general and specific combining ability in relation to diallel crossing systems. Aust. J. Biol. Sci. 9: 463-493.

Henderson, C. R. 1948. Estimation of general, specific and maternal abilities in crosses among inbred lines of swine. Diss. Iowa State College, Iowa, USA.

Jakubec, V., Komender, P., Nitter, G., Fewson, D. and Soukupova, Z. 1987: Crossbreeding in Farm-Animals .1. Analysis of Complete Diallel Experiments by Means of 3 Models with Application to Poultry. Journal of Animal Breeding and GeneticsZeitschrift Fur Tierzuchtung Und Zuchtungsbiologie 104: 283-294.

Mekki, D. M., Yousif, I. A., Abdel, R. M. K., Wang, J. Y. and Musa, H. H. 2005. Growth performance of indigenous $\times$ exotic crosses of chicken and evaluation of general and specific combining ability under Sudan condition, Int. J. Poult. Sci., 4, 468-471.

Mekki, D., M., Yousif, I. A., Abdel Rahman, M. K., Wang, J. Y. and Musa, H. H. 2005. Growth performance of indigenous $x$ exotic crosses of chicken and evaluation of general and specific combining ability under Sudan condition. Int. J. Poult. Sci., 4: 468-471.

Okoro, V. M. O. and Mbajiorgu, V. M. O. 2017. Estimates of crossbreeding parameters for growth and conformation traits in Nigerian indigenous and exotic pig breeds. Applied Ecology and Environmental Research, 15(4), 117-128.

Panter, D. M. and Allen, F. L. 1995. Using best linear unbiased predictions to enhance breeding for yield in soybean: I Choosing Parents. Crop Science 35: 397-405. 
Diallel crossbreeding, Genetic parameters, REML, ANOVA

\section{Ragab, M., Sánchez, J. P., Mínguez, C., Vicente, J. S., and Baselga, M. 2014. Litter size components in a full diallel cross of four maternal lines of rabbits 1 . 3231-3236.}

Razuki, W. M. and AL-Shaheen, S. A. 2011.Use of Full Diallel Cross to Estimate Crossbreeding Effects in Laying Chickens. International Journal of Poultry Science 10 (3): 197-204.

Resende, M. D. V. and Duarte, J. B. 2007. Precision and quality control in variety trials. Pesqui. Agropecu. Trop. 37: 182-194.

Resende, M. D. V. and Fernandes, J. C. S. 1999. Procedimento BLUP (melhor predição linear não viciada) individual para deline- amentos experimentais aplicados ao melhoramento flores- tal. Revista de Matemática e Estatística 17: 89-107.

Saadey, S. M., Galal, A., Zaky, H. I. and Zein el-dein, A. 2008. Diallel crossing analysis for body weights and egg production traits of two native Egyptian and two exotic chicken breeds, International Journal of Poultry Science, 7, 64-71.

Shebl, M. K. A, Ali M. A., Balat, M. M. and El-Din, T. H. 1990. Evaluation of combining ability for some body-size traits and feathering in a diallel cross of chickens. Egypt Poult. Sci. 10:159-177.

Siwendu, N. A., Norris, D., Jones, W., Hussein A. S., Benyi, K. 2013. Heterosis and combining ability for body weight in a diallel cross of three chicken genotypes. Trop Anim Health Prod, 45:965-970. DOI: https://10.1007/s11250-012-0317-8

Valério, I. P., Irajá, F., Carvalho, F. De, Oliveira, A. C. De. And Souza, V. Q. De. 2009. Combining ability of wheat genotypes in two models of diallel analyses. 100-107.

Vencovsky, R. 1987. Herança quantitativa. In: Melhoramento e produção do milho (Paterniani E and Viégas GP, eds.). Fundação Cargill, Campinas. 


$$
\text { الملخص العربى }
$$

تعليل الخلط المتبادل في الاجاج باستخدام طريقة معظمة الاحتمال المقيد (REML)

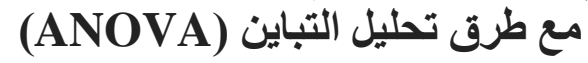

$$
\begin{aligned}
& \text { محمد حسن خليل * و جلال ابو خديجه** } \\
& \text { * قنم انتاج الدواجن كلية الزر اعة- جامعة الاسكندرية } \\
& \text { كلية الزر اعة البيئية والصحر اوية ـ فوكة -جامعة مطروح***. }
\end{aligned}
$$

تم إجر اء التجربة الحالية لمقارنة طريقة معظمة الاحتمال المقيد (REML) مع طرق تحليل التباين (ANOVA) في

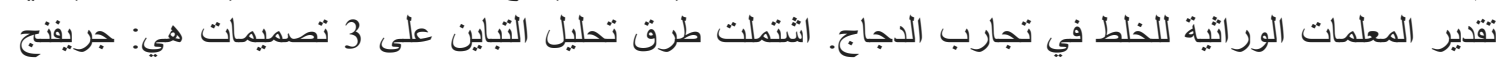

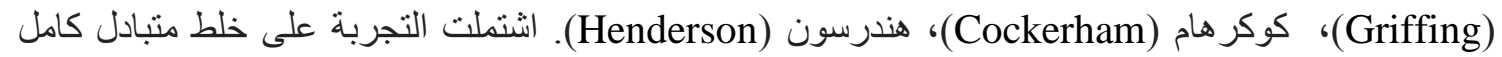

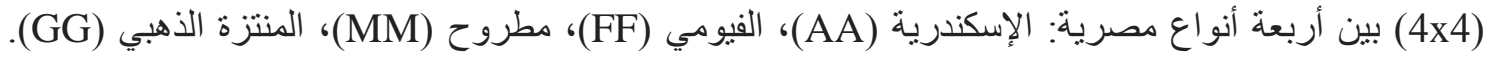

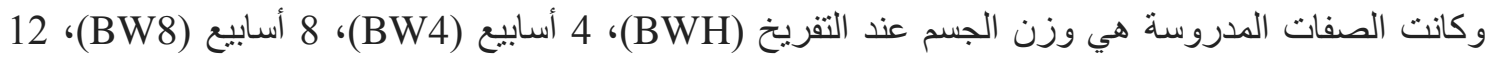

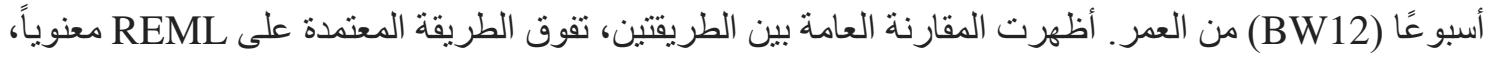

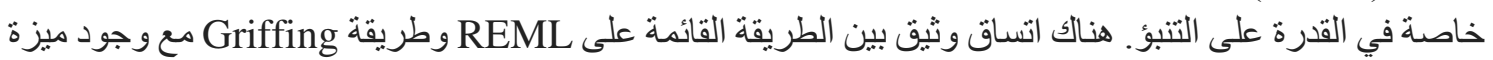

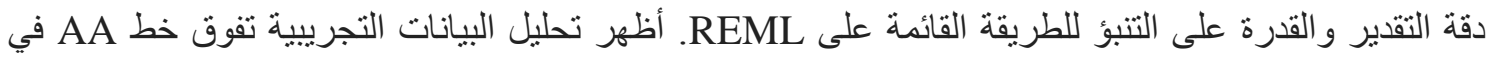

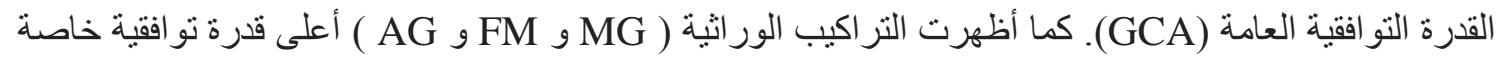
في نهاية التجربة عند عمر 12 أسبو عاً (SCA) 